\title{
Pathogenesis and biomarkers in ANCA-associated vasculitis
}

\author{
Sofia Almeida ${ }^{1, \#}$, Pedro Maia Neves ${ }^{1, \#}$, Vital Da Silva Domingues ${ }^{1,2, \#}$ \\ ${ }^{1}$ Serviço de Medicina, Centro Hospitalar e Universitário do Porto, Porto 4099-001, Portugal. \\ ${ }^{2}$ Inflammation and Lymphocyte Physiology Labs, Gulbenkian Institute of Science, Oeiras 270-156, Portugal. \\ ${ }^{\#}$ Authors contributed equally.
}

Correspondence to: Dr. Vital Da Silva Domingues, Serviço de Medicina, Centro Hospitalar e Universitário do Porto, Largo Prof. Abel Salazar, Porto 4099-001, Portugal. E-mail: vdomingues@igc.gulbenkian.pt

How to cite this article: Almeida S, Neves PM, Da Silva Domingues V. Pathogenesis and biomarkers in ANCA-associated vasculitis. Vessel Plus 2021;5:44. https://dx.doi.org/10.20517/2574-1209.2021.66

Received: 18 Apr 2021 First Decision: 18 May 2021 Revised: 20 Jun 2021 Accepted: 9 Jul 2021 First online: 13 Jul 2021

Academic Editor: Luca Quartuccio Copy Editor: Xi-Jun Chen Production Editor: Xi-Jun Chen

\begin{abstract}
Anti-neutrophil cytoplasmic antibody (ANCA)-associated vasculitides (AAVs) are a group of systemic autoimmune diseases associated with serum ANCA positivity that affect small to medium vessels with inflammation and endothelial injury. This group includes several diseases: granulomatosis with polyangiitis (GPA), microscopic polyangiitis, eosinophilic GPA, and drug-induced AAV. A few AAVs are ANCA negative, but this form has decreased with the increase in detection methods. Different genetic, epigenetic, and environmental risk factors contribute to the pathogenesis of AAV. ANCA's role in the origin of vasculitis has led to a better grasp of the disease. Research has also improved the treatment, more precisely to tune its intensity, translating into better outcomes. However, there is still a gap to be filled with new potential and testable biomarkers for diagnosis, disease activity, and prognosis, which we discuss here.
\end{abstract}

Keywords: Pathogenesis, ANCA, ANCA-associated vasculitis, biomarkers

\section{INTRODUCTION}

Anti-neutrophil cytoplasmic antibody (ANCA)-associated vasculitides (AAVs) are a group of systemic autoimmune diseases that affect small to medium vessels with inflammatory and endothelial injury. In the early 1980s, the first case report mentioning ANCA presence in the serum of patients with segmental necrotizing glomerulonephritis triggered a new chapter in immune-mediated diseases ${ }^{[1]}$. The discovery of 
the major antigens targets of ANCAs [myeloperoxidase (MPO) and proteinase 3 (PR3)] led to the creation of an inclusive group of AAVs. Classification criteria based on clinical findings and tissue biopsy, if possible or reasonable, have not always been widely accepted and new scores are being proposed ${ }^{[2,3]}$.

The AAV group incorporates at least four particular diseases: granulomatosis with polyangiitis (GPA), microscopic polyangiitis (MPA), eosinophilic GPA (EGPA; formerly Churg-Strauss syndrome), and druginduced $\mathrm{AAV}^{[4]}$.

GPA is a necrotizing small-vessel vasculitis characterized by the involvement of the respiratory tract with granulomatous inflammation. These patients are mainly PR3-ANCA positive. In contrast, MPA preferably targets renal glomeruli small vessels and presents a histological pattern of necrotizing vasculitis normally lacking granulomatous inflammation. The serum of these patients commonly presents MPO-ANCA positivity.

The EGPA histological pattern is similar to GPA, except its main feature of eosinophil-rich reaction that involves small- to medium-sized vessels. Patients with this disease typically have associated adult-onset asthma and allergic sinusitis, eosinophilia, tissue infiltrating eosinophils, and around 50\% of the cases have MPO-ANCA positivity.

Drugs such as propylthiouracil, hydralazine, or cocaine induce ANCA production and generate druginduced AAV. The clinical features of this particular spectrum of AAV have a wide and global variation according to ethnic differences ${ }^{[5]}$. More commonly, MPA- and MPO-ANCA positivity is observed in East Asian countries, while GPA- and PR3-ANCA is more noticeable in Western countries ${ }^{[6]}$.

Worldwide identification of these diseases prompted international guidelines and treatment management for remission and maintenance ${ }^{[7-9]}$. However, methods for the monitoring of AAVs activity are still lacking. In this review, we characterize the current knowledge regarding AAV's risk factors and pathogenesis and subsequently review newly discovered biomarkers for its diagnosis, monitoring, and prognosis.

\section{RISK FACTORS OF AAV}

A multiplicity of risk factors for AAV has been described in the literature, as summarized in Table 1.

\section{Genetics}

Even though familiar reports of AAV are $\operatorname{rare}^{[10]}$, as for other autoimmune disorders, genome-wide association studies (GWAS) have been performed to further identify alleles related with patterns of susceptivity or resistance to AAV. Among these, the strongest associations were found for major histocompatibility complex class II (MHC II) and HLA gene locus on chromosome 6.

The differences in HLA are related to the ethnicity of the population and the appearance of certain circulating antibodies rather than the clinical appearance ${ }^{[11]}$. A GWAS conduced in the UK found strong associations between HLA-DPB1 ${ }^{*} 04$ and PR3-ANCA (OR $\left.=7.03\right)$, MPO-ANCA and DQ loci (OR $\left.=0.65\right)$, and HLA-DP allele and GPA $(\mathrm{OR}=5.39)^{[11]}$. In Japan, population studies linked HLA-DRB $1^{*} 09: 01$ with MPO-ANCA $(\mathrm{OR}=1.57)$ and MPA $(\mathrm{OR}=1.56)$. Curiously, HLA-DRB1*13:02 was suggested as a protective factor against $\mathrm{AAV}^{[12]}$. 
Table 1. Anti-neutrophil cytoplasmic antibody-associated vasculitis risk factors

\begin{tabular}{|c|c|c|c|}
\hline \multicolumn{2}{|l|}{ Risk factor } & \multicolumn{2}{|r|}{ Evidence } \\
\hline Genetics & & \multicolumn{2}{|c|}{$\begin{array}{l}\text { Significant association HLA-DP locus and GPA; DQ loci and MPO-ANCA; HLA-DP allele and GPA } \\
\text { SERPINA-1, } \alpha-1 \text {-antitrypsin allele deficiency, proteinase } 3 \text { gene (PR3) polymorphism and variant } \\
\text { increasing PTPN22 activity }\end{array}$} \\
\hline Epigenetics & & \multicolumn{2}{|c|}{ MPO and PRTN3 promoter methylation } \\
\hline \multirow[t]{8}{*}{ Exposome } & Seasonality & \multicolumn{2}{|c|}{$\begin{array}{l}\text { Discrepant results in literature } \\
\text { Onset observed in autumn and winter months }\end{array}$} \\
\hline & $\begin{array}{l}\text { Latitude and UV } \\
\text { radiation }\end{array}$ & \multicolumn{2}{|c|}{$\begin{array}{l}\text { Increased prevalence of MPA and GPA in hot and cold countries, respectively } \\
\text { Higher latitudes correlate with higher GPA incidence }\end{array}$} \\
\hline & Infections & \multicolumn{2}{|c|}{$\begin{array}{l}\text { Exposure to toxic shock syndrome toxin-1 } \\
\text { Nasal S. aureus colonization related to relapse rates }\end{array}$} \\
\hline & \multirow[t]{3}{*}{ Pollution } & Silica & $\begin{array}{l}2.5 \text {-fold increased risk, even higher for patients with renal involvement, GPA or } \\
\text { MPA }\end{array}$ \\
\hline & & Farming & $\begin{array}{l}\text { GPA associated with } 12 \text { months prior-visits and significant livestock exposure } \\
\text { Gardening, namely digging, mowing and planting }\end{array}$ \\
\hline & & Other pollutants & Exposure to carbon monoxide, hydrocarbon and high organic solvent \\
\hline & Drugs & \multicolumn{2}{|c|}{ e.g., propylthiouracil, methimazole, hydralazine, minocycline or cocaine } \\
\hline & Smoking & \multicolumn{2}{|l|}{ Weak correlation } \\
\hline
\end{tabular}

GPA: Granulomatosis with polyangiitis; MPO: myeloperoxidase; ANCA: anti-neutrophil cytoplasmic antibody; MPA: microscopic polyangiitis.

Besides MHC genes, several single-nucleotide polymorphisms (SNP) associated with the AAVs have been found. The variant that increases the activity of PTPN22, which negatively regulates IL-10 (an immunosuppressive cytokine), increases the likelihood of PR3-ANCA (OR = 1.63). Oppositely, SNPs related to SERPINA1, PRTN3, and SEMA6A showed profiles protective against AAV ${ }^{[11]}$.

\section{Epigenetics}

Gene expression regulation of MPO and PRTN3 genes were linked to DNA methylation and histone 3 lysine 27 (H3K27me3). MPO and PRTN3 promoter methylation are negatively correlated with patients with active AAV and increase during remission of the disease ${ }^{[13]}$. H3 27 me3 trimethylation reduction was also associated with active disease by expressing aberrant MPO and PRTN3 genes ${ }^{[14]}$.

\section{Exposome}

The initial report of AAV was coupled with an infectious disease ${ }^{[1]}$. More recently, AAVs have been shown to be triggered by infectious agents, namely after exposure to toxic shock syndrome toxin-1, a toxin secreted by Staphylococcys aureus, and relapses have also been associated with higher nasal S. aureus colonization $^{[15,16]}$.

Many other factors appear to be related with higher risk for AAVs. Seasonality shows discrepant results in the literature, but AAVs, namely GPA, seem to have a more prevalent onset in autumn and winter months. The prevalence of AAV subtypes also seems linked with temperature, latitude, and UV radiation ${ }^{[17,18]}$.

As mentioned above, some drugs can precipitate AAV; thus, drug indications need to be weighed when studying the correlation between drugs and the risk for AAVs. Alopurinol seems to be the only drug that conferred a greater risk for developing GPA ${ }^{[19]}$.

The role of airborne particles has also been studied, with multiple approaches suggesting a higher disease risk when being exposed to certain pollutants, namely silica, carbon monoxide, hydrocarbons, and high organic solvents and particles associated with farming and gardening activities. As for smoking, there is a weak correlation to higher risk for developing the disease $\mathrm{e}^{[1,20-22]}$. 


\section{ANCA PATHOGENICITY \\ ANCA patterns}

Two major types of ANCA can be detected by indirect immunofluorescence of ethanol-fixated neutrophils. Perinuclear ANCAs (p-ANCAs) stain around the nucleus and are mainly composed of myeloperoxidase. Conversely, some ANCAs stain diffusely in the cytoplasm, namely cytoplasmatic ANCAs (c-ANCAs), of which the most important is PR3. Other "minor" ANCAs have been described: against $\alpha$-enolase, azurocidin, bactericidal permeability-increasing protein (BPI), cathepsin G, elastase, defensin, lactoferrin, lysosome-associated membrane glycoprotein 2 (LAMP2), and moesin. These antibodies are mainly pANCAs and are rarely associated with vasculitis. Nowadays, enzyme-linked immunosorbent assay (ELISA) tests detect MPO and PR3 instead of p-ANCAs and c-ANCAs, which correspond to the staining pattern ${ }^{[15]}$.

\section{ANCA production}

Neutrophils participate in the innate immune defense. These cells form networks of extracellular fibers, primarily composed of DNA from neutrophils, which bind pathogens ${ }^{[23]}$, the so-called neutrophil extracellular traps (NETs). An imbalance in NETs' production is known to participate in ANCA production. These traps are degraded by serum DNAse I. Nevertheless, in some circumstances, as in the case of propylthiouracil administration, NETs become resistant to DNAse I. The overexposure to NETs promotes the production of autoantibodies against neutrophils. Meanwhile, the traps are formed, and the content of neutrophilic granules, including PR3 and MPO, becomes mixed with chromatin fibers, which bind to DNA. By this physiological step, the antigenicity of PR3 and MPO might suffer modifications ${ }^{[24]}$. However, only a second step that prevents a complete degradation of NETs seems to be specific to some autoimmune diseases, such as AAVs and systemic lupus erythematosus ${ }^{[24,25]}$. This impaired NET degradation coincides with the lower serum DNAse I activity observed in patients with AAV when compared to healthy individuals ${ }^{[26]}$. Moreover, a later step triggers the autoimmune reaction by presenting misfolded proteins/antigens, in which cryptic epitopes are then recognized in class II MHC molecules by the immune system ${ }^{[27]}$.

\section{PATHOGENESIS OF AAV}

Facing a bacterial or viral infection, dendritic cells produce tumor necrosis factor (TNF)- $\beta$ and interleukin- 6 (IL-6). These inflammatory markers stimulate the differentiation of T cells into T helper 17 (Th17). In turn, Th17 cells produce IL-17, an important cytokine that can induce the production of TNF- $\alpha$ or IL-1 $\beta$ by macrophages. These proinflammatory cytokines then prime the innate immune system, namely neutrophils and the formation of ANCAs. Additionally, the autoreactive response is sustained by imbalances of $\mathrm{T}$ regulatory cells (Treg) that regulate the differentiation of Th17 and are associated with increased risk of $\mathrm{AAV}^{[28,22]}$.

The priming of the neutrophil also occurs by the complement system, namely C5a by the altern complement pathway, as described in animal models ${ }^{[30]}$, which is related to hypercoagulability states in patients with AAV due to tissue factor release ${ }^{[31]}$.

Upon priming, neutrophils express surface ANCA antigens. These ANCAs, besides binding to the corresponding antigens, also bind to the Fc $\gamma$ receptor in neutrophils. This positive feedback induces an excessive activation of these neutrophils, promoting cytokine production and reactive oxygen species and lytic enzymes release ${ }^{[32]}$, further incrementing the inflammatory status. ANCA-stimulated neutrophils release NETs that contribute to the local inflammatory response and epithelial damage [Figure 1]. At the same time, more neutrophils are activated either directly by NETs or indirectly by circulating ANCA. 

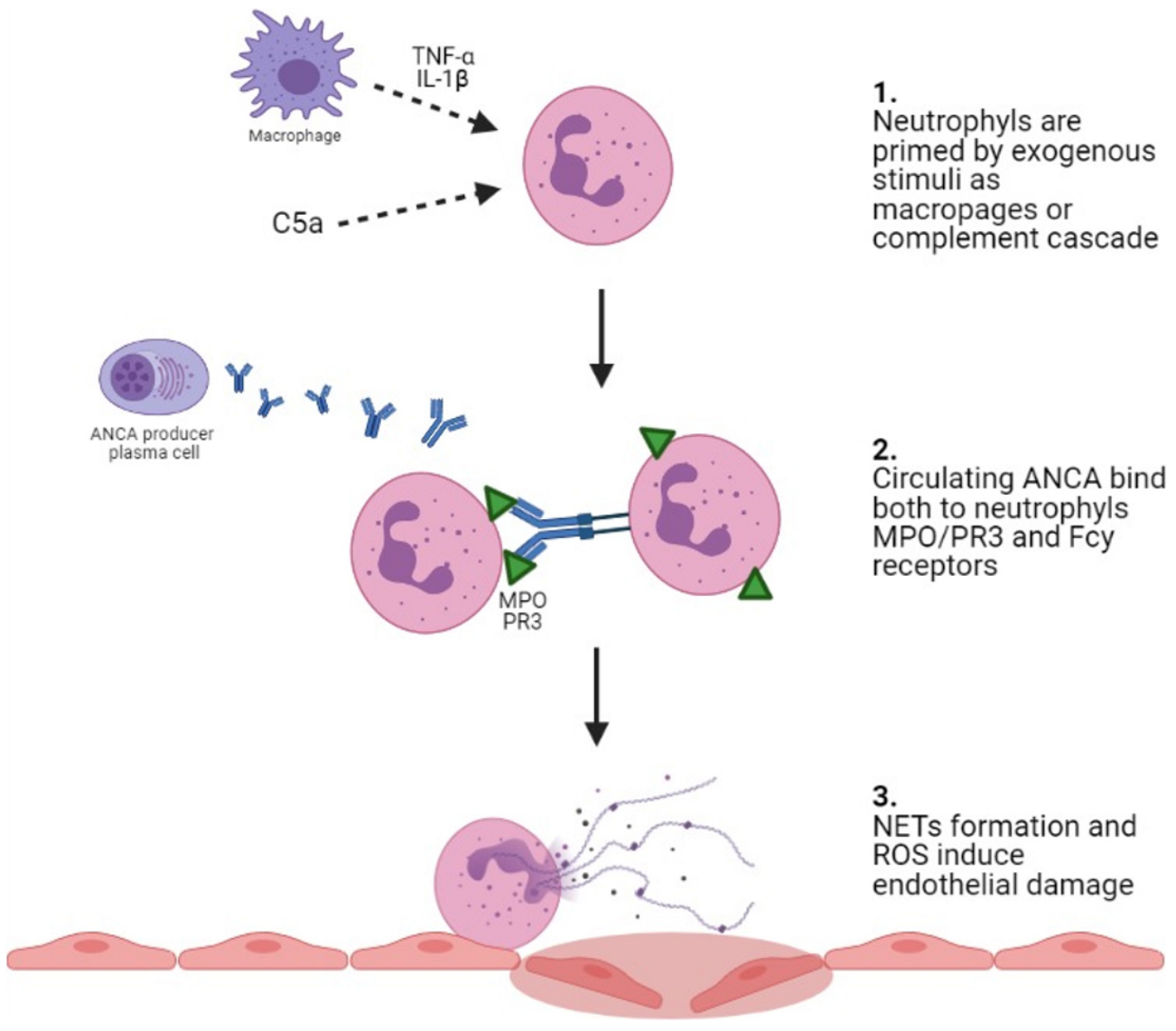

Figure 1. The inflammation cascade of anti-neutrophil cytoplasmic antibody (ANCA)-antibody associated vasculitis. ANCAs produced by plasma cells bind to myeloperoxidase and proteinase 3 produced by activated neutrophils (mediated by factors such as TNF- $\alpha$ or IL-1 $\beta$ ). The neutrophil activation stimulates more neutrophils, leading to the production of extracellular traps (NET) and reactive oxygen species, leading to tissue damage, granulomatosis, and necrosis (image created in biorender.com). MPO: Myeloperoxidase; PR3:

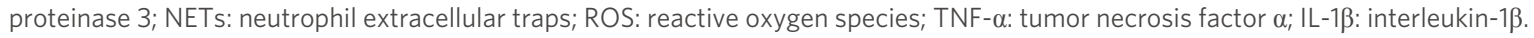

$\mathrm{B}$ cells are also activated by $\mathrm{CD} 4^{+} \mathrm{T}$ presenting cells, through the presentation of antigens resulting from $\mathrm{NETs}^{[33]}$. Another important mechanism may be by the release of B-cell-activating factor (BAFF) or Blymphocyte stimulator (BLyS) from activated neutrophils ${ }^{[33]}$.

In GPA, chronic exposure to Staphylococcus aureus by nasal mucosa colonization might be the pathogenic trigger ${ }^{[34]}$, by priming a local innate immune response that, under the right circumstances, may end up in AAV development. In the case of EGPA, which features eosinophilia, a vascular endothelial cell release of eotaxin 3 has been implicated in the tissue infiltration of eosinophils. These eosinophils secrete major basic proteins, eosinophilic cationic proteins, and neurotoxins that destroy the tissue ${ }^{[35]}$. Despite this particularity, the mechanism of MPO-ANCA production in these patients is still undisclosed.

\section{BIOMARKERS IN AAV}

Finding non-invasive markers capable of diagnosis and predicting disease activity, prognosis, and therapeutic options is a well desired goal for numerous studies related to AAV. As such, many studies have focused on the search for practical non-invasive markers to track AAV, as discussed below and summarized in Table 2. 
Table 2. Anti-neutrophil cytoplasmic antibody-associated vasculitis biomarkers and their usefulness

\begin{tabular}{|c|c|c|c|}
\hline Approach & Biomarker & Function & Description \\
\hline \multirow[t]{5}{*}{ Diagnosis } & PR3-ANCA and MPO-ANCA & $\begin{array}{l}\text { Distinguish from healthy patients } \\
\text { and between AAV subtypes }\end{array}$ & $\begin{array}{l}\text { Present in patients with GPA and MPA subtypes, } \\
\text { respectively }\end{array}$ \\
\hline & cfDNA & $\begin{array}{l}\text { Distinguish between AAV } \\
\text { subtypes }\end{array}$ & $\begin{array}{l}\text { Increased levels of cfDNA in PR3-ANCA GPA patients } \\
\text { compared to }\end{array}$ \\
\hline & sCD163 & Distinguish from healthy patients & Higher urinary levels of sCD163 in patients with AAV \\
\hline & $\begin{array}{l}\text { Eotaxin-3, IgG4 and } \\
\text { CCL17/TARC }\end{array}$ & $\begin{array}{l}\text { Distinguish between AAV } \\
\text { subtypes }\end{array}$ & $\begin{array}{l}\text { Increased levels of Eotaxin-3, lgG4 and CCL17/TARC in } \\
\text { EGPA compared to other AAV subtypes }\end{array}$ \\
\hline & 12-HETE & $\begin{array}{l}\text { Distinguish between AAV } \\
\text { subtypes }\end{array}$ & $\begin{array}{l}\text { Higher exhaled breath concentrations of } 12-\mathrm{HETE} \text { in EGPA } \\
\text { patients than healthy patients }\end{array}$ \\
\hline \multirow[t]{2}{*}{ Prognosis } & $\begin{array}{l}\text { Recognizable N-terminus of } \\
\text { MPO heavy chain }\end{array}$ & Evaluate disease prognosis & $\begin{array}{l}\text { Recognizable } \mathrm{N} \text {-terminus of MPO heavy chain are more } \\
\text { prone to develop severe disease }\end{array}$ \\
\hline & $\mathrm{C} 3$ & Evaluate disease prognosis & Low serum C 3 levels is associated with poorer outcomes \\
\hline \multirow[t]{11}{*}{ Disease activity } & PTX3+ and $\mathrm{HMGB}+$ & Distinguish disease activity status & $\begin{array}{l}\text { Concentrations of } \mathrm{PTX} 3+\text { and } \mathrm{HMGB}+\text { were higher in } \\
\text { active } \mathrm{AAV} \text { compared to remission }\end{array}$ \\
\hline & cfDNA & Distinguish disease activity status & $\begin{array}{l}\text { Concentration levels are higher in disease activity phases } \\
\text { namely in PR3-ANCA positive GPA }\end{array}$ \\
\hline & MCP-1, AGP, KIM-1, NGAL & Detect renal flares & $\begin{array}{l}\text { Urinary levels of MCP-1, AGP, KIM-1, NGAL are increased } \\
\text { in renal flares of AAV }\end{array}$ \\
\hline & sCD163 & Distinguish disease activity status & Higher urinary levels of sCD163 in disease activity phases \\
\hline & ESR, CRP and Calprotectin & Distinguish disease activity status & $\begin{array}{l}\text { Higher levels of ESR, CRP and Calprotectin in disease } \\
\text { activity phases }\end{array}$ \\
\hline & $\begin{array}{l}\text { Eotaxin-3, lgG4 and } \\
\text { CCL17/TARC }\end{array}$ & Distinguish disease activity status & $\begin{array}{l}\text { Increased levels of Eotaxin-3, lgG4 and CCL17/TARC in } \\
\text { disease activity phases }\end{array}$ \\
\hline & SRAGE & Distinguish disease activity status & Assessing mild/limited disease activity \\
\hline & EMPs and CECs & Distinguish disease activity status & $\begin{array}{l}\text { EMPs and CECs levels positively correlate with disease } \\
\text { activity }\end{array}$ \\
\hline & $\begin{array}{l}\mathrm{CD} 25^{+} \mathrm{T} \text {-cells } \\
\text { Th17 cells }\end{array}$ & Distinguish disease activity status & $\begin{array}{l}\text { CD } 25^{+} \text {T-cells inversely correlate with disease activity } \\
\text { Th17 cells positively correlate with disease activity }\end{array}$ \\
\hline & $\begin{array}{l}\text { T follicular helper (Tfh) cells } \\
\text { Tfh2/Tf1 ratio }\end{array}$ & Distinguish disease activity status & $\begin{array}{l}\text { Tfh cells positively correlate with disease activity } \\
\text { Tfh2/Tfh1 ratio shift }\end{array}$ \\
\hline & $\begin{array}{l}\mathrm{Bb}, \mathrm{C} 3 \mathrm{a}, \mathrm{C} 5 \mathrm{a} \text { and soluble } \\
\mathrm{C} 5 \mathrm{~b}-9\end{array}$ & Distinguish disease activity status & $\begin{array}{l}\mathrm{Bb}, \mathrm{C} 3 \mathrm{a}, \mathrm{C} 5 \mathrm{a} \text { and soluble } \mathrm{C} 5 \mathrm{~b}-9 \text { urinary levels positively } \\
\text { relate with disease activity. }\end{array}$ \\
\hline \multirow[t]{5}{*}{ Relapse risk } & PR3-ANCA & Evaluate relapse risk & $\begin{array}{l}\text { Increased PR3-ANCA levels positively relate with higher } \\
\text { relapse risk }\end{array}$ \\
\hline & Calprotectin & Evaluate relapse risk & Elevated calprotectin levels in patients who relapsed \\
\hline & EPCs & Evaluate relapse risk & $\begin{array}{l}\text { Reduced levels of EPCs positively relate with higher relapse } \\
\text { risk }\end{array}$ \\
\hline & B-cells & Evaluate relapse risk & $\begin{array}{l}\text { Incomplete B-cell depletion and B-cell repopulation after } \\
\text { rituximab treatment relate with higher relapse rate }\end{array}$ \\
\hline & CD8+ T-cells & Evaluate relapse risk & $\begin{array}{l}\text { CD8+ T-cells levels positively relate with higher relapse } \\
\text { risk }\end{array}$ \\
\hline $\begin{array}{l}\text { Response to } \\
\text { treatment }\end{array}$ & PR3-ANCA & Evaluate response to treatment & $\begin{array}{l}\text { PR3-ANCA positive respond better to treatment with } \\
\text { Rituximab }\end{array}$ \\
\hline
\end{tabular}

GPA: Granulomatosis with polyangiitis; MPO: myeloperoxidase; ANCA: anti-neutrophil cytoplasmic antibody; MPA: microscopic polyangiitis; AAV: associated vasculitides; ESR: erythrocyte sedimentation rate; CRP: C-reactive protein; EGPA: eosinophilic GPA; EMPs: endothelial microparticles; EPCs: endothelial progenitor cells.

\section{ANCA}

The value of ANCA as a diagnostic marker is mainly irrefutable. Occasional cases of "ANCA-negative" AAV are acknowledged, decreasing by the day with ANCA testing methodology improvement ${ }^{[36,37]}$. Falsenegative results can still be found because in some cases ANCA binds to the circulating ceruloplasmin ${ }^{[38]}$. 
The value of ANCA goes beyond its simple diagnostic value. The ANCA-positive patient subtypes, namely PR3-ANCA and MPO-ANCA, differ from one another regarding genetic basis, epidemiology, clinical manifestations, histological findings, response to therapy, and pathogenesis. These facts sustain the reason to distinguish between PR3-ANCA and MPO-ANCA patients, meaning GPA (commonly associated with PR3-ANCA) and MPA (commonly associated with MPO-ANCA) ${ }^{[36,39]}$.

Whereas the ANCA diagnostic value is no longer under doubt, its role as a disease activity marker has been the subject of frequent studies with varying outcomes ${ }^{[40]}$. Discrepant results regarding disease activity have been a matter of discussion in the literature ${ }^{[41-43]}$. This misalignment in the results can be interpreted by differences in the epitopes and affinities of ANCAs. Patients with a recognizable N-terminus of MPO heavy chain are more prone to develop a severe disease ${ }^{[44]}$, while patients with low-affinity despite high titers of MPO-ANCA have a lower vasculitic disease activity ${ }^{[45]}$. Some clinical studies show a direct link between an increment in PR3-ANCA levels during complete remission and an increased risk of relaps ${ }^{[46,47]}$, while others find a direct link between PR3-ANCA-positive patients and relapse probability compared to MPO-ANCA patients ${ }^{[48,49]}$.

The role of ANCA subtypes in predicting response to treatment is also a subject under scrutiny. Some studies suggest that adult PR3-ANCA-positive patients respond better to rituximab than to conventional induction/remission maintenance treatment with cyclophosphamide and azathioprine, leading to the belief that ANCA serotype may guide the type of treatment in $\mathrm{AAV}^{[50]}$.

\section{Biomarkers derived from neutrophil activation - NMPs and NETs}

Neutrophil microparticles (NMPs) are membrane vesicles that induce endothelial damage in AAV, whereas NETs, composed of DNA, histones, and neutrophil proteins and released by ANCA-stimulated neutrophils, contain antigenic components including $\mathrm{PR} 3$ and $\mathrm{MPO}^{[51]}$.

Removal of NMPs by filtration abolished a pathological trigger connected to endothelial activation, suggesting a target for therapeutic plasma exchange in AAV. Despite the suggestion, clinical utility remains unvalidated. A recent study concluded that MPO patients' NMPs express higher levels of pentraxin-3 (PTX3), high mobility group box 1 protein (HMGB1), and tumor necrosis factor-like weak inducer of apoptosis (TWEAK) when compared to healthy controls ${ }^{[52]}$. Concentrations of $\mathrm{PTX}_{3}{ }^{+}$and $\mathrm{HMGB}^{+}$were significantly higher in active AAV patients compared to those in remission ${ }^{[52]}$. PTX3 serum levels were strongly correlated with the Birmingham vasculitis activity score ${ }^{[52]}$.

Moreover, Lange et al. ${ }^{[53]}$ detected a significant increase in serum circulating free DNA (cfDNA) levels in PR3-ANCA GPA patients compared to EGPA and concluded that there is an association between concentration of cfDNA and disease activity. These findings suggest that abnormal formation and/or insufficient clearance of NETs may contribute to increase the levels of cfDNA in GPA. The detection of cfDNA levels or NETs may serve as a marker of disease activity in AAV, namely PR3-ANCA-positive $\mathrm{GPA}^{[53,54]}$.

\section{Urinary biomarkers}

Urinary biomarkers could be ideal for the non-invasive monitoring of disease activity and renal involvement.

Lieberthal et al..$^{[55]}$ found that urinary levels of monocyte chemotactic protein 1 (MCP-1), $\alpha-1$-acid glycoprotein (AGP), kidney injury molecule 1 (KIM-1), and neutrophil gelatinase-associated lipocalin 
(NGAL) presented statistically significant increases during renal flares among patients with AAV. Of those, MCP-1 chemokine granted the best discrimination between active renal disease and remission ${ }^{[55]}$. MCP-1 is in fact the most promising urinary biomarker for AAV still under research, with multiple studies suggesting usefulness in the assessment of vasculitis and monitoring treatment ${ }^{[55-57]}$.

Urinary soluble CD163 was presented as an even more promising biomarker of renal vasculitis than urinary MCP- $1^{[58]}$. CD163 is a soluble form of a high affinity scavenger receptor for the hemoglobin-haptoglobin receptor complex and functions as an innate sensor for bacteria. Patients with small vessel vasculitis (which includes GPA, MPA, and EGPA) had markedly higher urinary sCD163 levels than patients in remission, disease controls, or healthy controls ${ }^{[58]}$. However, serum $\mathrm{SCD} 163$ levels failed to distinguish infections from active disease, which may limit its use ${ }^{[59]}$.

\section{Inflammatory markers}

Traditional inflammatory markers such as ESR (erythrocyte sedimentation rate) or CRP (C-reactive protein) are non-specific markers for AAV.

Monach et al. ${ }^{[60]}$ evaluated whether these markers were able to distinguish severe AAV [BVAS for Wegener's granulomatosis (BVAS/WG) $\geq 3$ at screening] from remission. All subjects with severe active vasculitis at screening were followed during remission at Month 6, of whom 24 out of 28 showed significant decline ${ }^{[60]}$. Although they are not specific, traditional inflammatory markers correlate with the activity of the disease.

Eosinophilia is the hallmark of EGPA; however, the number of circulating eosinophils may not be an adequate biomarker for active EGPA since the eosinophil count usually drops dramatically and rapidly after treatment with glucocorticoids. Indeed, the treatment effect, mainly glucocorticoids, may directly cause the mispresenting comparison between active and inactive EGPA. Eotaxin-3, immunoglobulin G4 (IgG4), and CC chemokine ligand 17 (CCL17/TARC) levels were higher in active EGPA compared to healthy controls, inactive EGPA, and/or other diseases featuring vasculitis or hypereosinophilia ${ }^{[35,61,62]}$. Interestingly, eotaxin-3 levels were lower in hypereosinophilic syndromes than EGPA, underpinning a potential diagnosis use ${ }^{[35,61]}$.

Pepper et al ${ }^{[63]}$ suggested calprotectin as a potential disease biomarker in patients with AAV by showing that patients with AAV had higher monocyte and neutrophil cell surface calprotectin expression than healthy controls and that its levels increased following treatment withdrawal and were significantly elevated in patients who relapsed.

12-Hydroxyeicosatetraenoic acid (12-HETE) measurement in exhaled breath concentrates (EBC) is a very different approach to distinguishing EGPA from asthma or hypereosinophilic syndromes. Szczeklik et al. ${ }^{[6]}$ identified markedly higher concentrations of 12-HETE in EBC of EGPA than of other compared diseases, even though 19 out of 23 patients were receiving glucocorticoids and one third were clinically in remission.

Clinical trials also provide promising markers, such as MMP-3, TIMP-1, and CXCL13 (BCA-1) $)^{[60]}$, which need further investigation with proper endpoints. sRAGE (serum advanced glycation end products) is another particular biomarker that may reflect the burden of granulomatous inflammation in $\mathrm{GPA}^{[65]}$ and therefore be useful for assessing mild/limited disease activity.

\section{Endothelial damage biomarkers}

Two important biomarkers of endothelial injury were studied in AAV: endothelial microparticles (EMPs) and circulating detached mature endothelial cells (CECs). 
EMPs are complex vesicular structures released from activated or apoptotic endothelial cells that play a singular role in inflammation, coagulation, endothelial function, and angiogenesis. Their dysregulation disturbs the vascular homeostasis, contributing to the progression of vascular diseases, such as vasculitis $^{[6,67]}$. For this reason, research on EMPs identified a positive correlation with disease activity when compared with patients in remission ${ }^{[68]}$. These same EMPs may generate excess thrombin and thrombotic complications, namely in children with systemic vasculitis ${ }^{[6]]}$ and cerebral vasculitis of the young ${ }^{[70]}$.

CECs have also been described as a biomarker of disease activity in vasculitis ${ }^{[7]}$. These are necrotic, highly activated endothelial cells that detach from the vessel wall and positively correlate with vasculitis in adults and children ${ }^{[67,71]}$. Upon endothelial lesion, bone marrow-derived endothelial progenitor cells (EPCs) increase in order to perform endothelial repair. These events have been described to be predictive of early relapse in adults with AAV, in whom a reduced number of circulating EPCs has been observed ${ }^{[72]}$.

Von Willebrand factor (VWF) is yet another biomarker of disease to be confirmed in adult AAV patients. This plasma protein, synthesized primarily by megakaryocytes and endothelial cells, mediates platelet aggregation and adhesion. VWF levels increase in response to endothelial injury or activation, and it has been described as a biomarker of disease activity in childhood CNS vasculitis that was not confirmed in adults $^{[70,73]}$.

\section{B cell, T cell, and cytokines}

B-cell subset populations have drawn study interest, with data from observational studies suggesting that incomplete B-cell depletion and B-cell repopulation after rituximab treatment is associated with a significantly higher relapse rate ${ }^{[74,75]}$.

B-cell subset populations of interest include regulatory B cells (Bregs), such as $\mathrm{CD}^{+}$cells $^{[40]}$. Measurement of Bregs showed initial promise with a lower $\mathrm{CD}^{+} \mathrm{B}$-cell count correlating with active disease, but a subsequent analysis from the RAVE study found that this count was not predictive of disease relapse, severity, or treatment failure $\mathrm{e}^{[76,77]}$.

In some studies, elevated levels of B-cell activating factor (BAFF) have been found in patients with AAV active disease, with a corresponding fall after treatment. However, BAFF levels are affected by corticosteroid treatment, rendering it an inadequate biomarker in $\mathrm{AAV}^{[78]}$.

T-cell involvement in AAV was previously discussed. CD25 and CD28 T-cell markers were already correlated with disease activity. $\mathrm{CD} 25^{+}$marker on $\mathrm{T}$ cells was inversely related to disease activity, however it is not clear if its population reflects a cause or effect of the disease ${ }^{[39]}$. CD2 $28^{+} \mathrm{T}$ cells are associated with a high risk of relapse, displaying markers associated with T-cell survival and memory T-cell levels; thus, the $\mathrm{CD}^{+} \mathrm{T}$-cell profile might be able to identify a group of AAV patients more likely to relapse ${ }^{[39]}$. Another subset of T cells, Th17 cells, has been identified as a potential driver of the disease. Th17 cells seem to be autoantigen-specific and are also spotted in renal lesions of AAV patients ${ }^{[79]}$. von Borstel et al. ${ }^{[80]}$ analyzed $\mathrm{CD} 19^{+} \mathrm{CD} 24^{\text {hi }} \mathrm{CD} 38^{\text {hi }} \mathrm{B}$ cells from the peripheral blood of AAV patients in remission and healthy controls. They found a negative correlation between Th17 cells and Breg and concluded that Th17 cells in AAV patients are at least partially controlled by Breg, highlighting another population that may be responsible for the disease and a target for its control ${ }^{[80]}$. Indeed, targeting B cells by the use of rituximab has shown a sustained remission at Month 28 when compared with other maintenance options ${ }^{[81,82]}$. However, as discussed above, B-cell activity has not been predictive of disease relapse. Other research groups found that an imbalance of Th17 and regulatory T (Treg) cells may also be of potential use to monitor AVV patients 
with renal involvement ${ }^{[83]}$. An increase of Th17 cells and a decrease of Treg cells, along with a downward trend for IL-2 and IL-4 and an upward one for IL-6, IL-10, TNF- $\alpha$, IFN- $\gamma$, and IL-17A, were observed in AVV patients ${ }^{[83]}$.

$\mathrm{T}$ follicular helper (Tfh) cells and $\mathrm{T}$ follicular regulatory (Tfr) cells balance is critical for humoral immune responses and relevant in autoimmune diseases ${ }^{[84]}$. AVV patients present increased circulating Tfh cells $\left(\mathrm{CD} 4^{+} \mathrm{CXCR} 5^{+} \mathrm{CD} 25^{-} \mathrm{CD} 127^{\text {interm-hi }}\right)$, decreased $\mathrm{Tfr}$ cells $\left(\mathrm{CD} 4^{+} \mathrm{CXCR} 5^{+} \mathrm{CD} 25^{+} \mathrm{CD} 127^{\text {lo-interm }}\right)$, and elevated $\mathrm{Tfh} / \mathrm{Tfr}$ ratios compared with healthy control ${ }^{[84]}$. Moreover, this study observed a Tfh2/Tfh 1 shift and increased plasma IL-21 level associated with AAV and disease activity ${ }^{[8]}$. This suggests Tfh phenotype as a promising biomarker for AVV disease activity.

\section{Complement}

Alternative complement pathway activation is a fundamental way of developing disease. Gou et al ${ }^{[85]}$ found that urinary levels of $\mathrm{Bb}, \mathrm{C} 3 \mathrm{a}, \mathrm{C} 5 \mathrm{a}$, and soluble C5b-9 were significantly higher in active disease.

Recently, the role of C5a in ANCA-induced neutrophil activation was shown, relating the generation of C5a by supernatants from ANCA-stimulated neutrophils with the role of C5a mediated effects via its specific receptor, allowing neutrophils to generate ROS in response to $\mathrm{ANCA}^{[31]}$. It was demonstrated that the lack of C5a receptor induces resistance to ANCA-induced disease, namely experimental anti-MPO vasculitis with the significant attenuation of the neutrophil glomerular influx and lower albuminuria, showing a potential therapeutic target in $\mathrm{AAV}^{[86]}$.

In the first AAV human study of C5a, Yuan et al. ${ }^{[87]}$ demonstrated higher levels of C5a in patients with active AAV compared with AAV in remission. Similarly, plasma levels of fragment $\mathrm{Bb}$ were significantly higher in active AAV than in patients in remission or healthy controls. Those levels positively correlated with the number of crescents on renal histology, vasculitis activity score, and serum inflammatory markers ${ }^{[88]}$. More recently, the ADVOCATE study group investigated an C5 receptor inhibitor in patients with ANCA-associated vasculitis-avacopan, which proved noninferior but not superior to prednisone taper with respect to remission at Week 26 and was superior to prednisone taper with respect to sustained remission at Week $52^{[89]}$. This result represents a role for $\mathrm{C} 5$ as a possible biomarker, as described above in the pathogenesis of the disease.

Finally, Manenti et al. ${ }^{[90]}$ reported that low serum C3 levels at diagnosis is associated with poorer patient and renal outcomes in AAV patients; however, there were no significant association between serological and pathohistological phenotypes and serum C3 levels.

\section{CONCLUSION}

In this review, we discuss an updated understanding of the pathogenesis and novel biomarkers of AAV. The knowledge gap in the pathophysiology and follow-up of AAV diseases has raised research interest. Innovations in methodology, such as modern "omics", and new discoveries from other fields have incremented the AAV pathogenesis perception. Genetic, epigenetic, and environmental factors identification, along with the role of neutrophils, other immune cells, and humoral factor contributions, have now contributed to another milestone in AAV research. However, disease activity monitoring, treatment, and relapse prediction are not yet effective. Our most recent knowledge on the pathogenesis is identifying pivotal players in this disease and engendering new biomarkers soon to be studied in clinical settings. However, the demonstration of either the very high sensitivity or the very high specificity of new biomarkers has not yet reached clinically relevant outcomes. 
Future collaborative research and interactions between basic and clinical research would be a good strategy for the comprehensive understanding of the etiology and pathogenesis of AAV and ultimately for improving the diagnosis, treatment, and prognosis of these patients.

\section{DECLARATIONS}

\section{Authors' contributions}

Wrote and reviewed the biomarkers: Almeida S

Wrote and reviewed the pathogenesis: Neves MP

Wrote and reviewed the introduction: Da Silva Domingues V

All authors contributed for the final version of the paper.

\section{Availability of data and materials}

Not applicable.

\section{Financial support and sponsorship}

None.

\section{Conflicts of interest}

All authors declare that there are no conflicts of interest.

\section{Ethical approval and consent to participate}

Not applicable.

\section{Consent for publication}

Not applicable.

\section{Copyright}

(c) The Author(s) 2021.

\section{REFERENCES}

1. Davies DJ, Moran JE, Niall JF, Ryan GB. Segmental necrotising glomerulonephritis with antineutrophil antibody: possible arbovirus aetiology? Br Med J (Clin Res Ed) 1982;285:606. DOI PubMed PMC

2. Kitching AR, Anders HJ, Basu N, et al. ANCA-associated vasculitis. Nat Rev Dis Primers 2020;6:71. DOI PubMed

3. Seeliger B, Sznajd J, Robson JC, et al. Are the 1990 American College of Rheumatology vasculitis classification criteria still valid? Rheumatology (Oxford) 2017;56:1154-61. DOI PubMed PMC

4. Jennette JC, Falk RJ, Bacon PA, et al. 2012 revised International Chapel Hill Consensus Conference Nomenclature of Vasculitides. Arthritis Rheum 2013;65:1-11. DOI PubMed

5. Pearce FA, Craven A, Merkel PA, Luqmani RA, Watts RA. Global ethnic and geographic differences in the clinical presentations of anti-neutrophil cytoplasm antibody-associated vasculitis. Rheumatology (Oxford) 2017;56:1962-9. DOI PubMed

6. Furuta S, Chaudhry AN, Arimura Y, et al. Comparison of the Phenotype and Outcome of Granulomatosis with Polyangiitis Between UK and Japanese Cohorts. J Rheumatol 2017;44:216-22. DOI PubMed

7. Bossuyt X, Cohen Tervaert JW, Arimura Y, et al. Position paper: Revised 2017 international consensus on testing of ANCAs in granulomatosis with polyangiitis and microscopic polyangiitis. Nat Rev Rheumatol 2017;13:683-92. DOI PubMed

8. Puéchal X, Pagnoux C, Perrodeau É, et al; French Vasculitis Study Group. Long-term outcomes among participants in the WEGENT trial of remission-maintenance therapy for granulomatosis with polyangiitis (Wegener's) or microscopic polyangiitis. Arthritis Rheumatol 2016;68:690-701. DOI PubMed

9. Yates M, Watts RA, Bajema IM, et al. EULAR/ERA-EDTA recommendations for the management of ANCA-associated vasculitis. Ann Rheum Dis 2016;75:1583-94. DOI PubMed

10. Tanna A, Salama AD, Brookes P, Pusey CD. Familial granulomatosis with polyangiitis: three cases of this rare disorder in one Indoasian family carrying an identical HLA DPB1 allele. BMJ Case Rep 2012;2012:bcr0120125502. DOI PubMed PMC

11. Lyons PA, Rayner TF, Trivedi S, et al. Genetically distinct subsets within ANCA-associated vasculitis. N Engl J Med 2012;367:21423. DOI PubMed PMC

12. Kawasaki A, Hasebe N, Hidaka M, et al. Protective role of HLA-DRB1*13:02 against microscopic polyangiitis and MPO-ANCApositive vasculitides in a Japanese Population: a Case-Control Study. PLoS One 2016;11:e0154393. DOI PubMed PMC 
13. Jones BE, Yang J, Muthigi A, et al. Gene-specific DNA methylation changes predict remission in patients with ANCA-associated vasculitis. J Am Soc Nephrol 2017;28:1175-87. DOI PubMed PMC

14. Ciavatta DJ, Yang J, Preston GA, et al. Epigenetic basis for aberrant upregulation of autoantigen genes in humans with ANCA vasculitis. J Clin Invest 2010;120:3209-19. DOI PubMed PMC

15. Nakazawa D, Masuda S, Tomaru U, Ishizu A. Pathogenesis and therapeutic interventions for ANCA-associated vasculitis. Nat Rev Rheumatol 2019;15:91-101. DOI PubMed

16. Laudien M, Gadola SD, Podschun R, et al. Nasal carriage of Staphylococcus aureus and endonasal activity in Wegener's granulomatosis as compared to rheumatoid arthritis and chronic Rhinosinusitis with nasal polyps. Clin Exp Rheumatol 2010;28:51-5. PubMed

17. Scott J, Hartnett J, Mockler D, Little MA. Environmental risk factors associated with ANCA associated vasculitis: a systematic mapping review. Autoimmun Rev 2020;19:102660. DOI PubMed

18. Watts RA, Gonzalez-Gay MA, Lane SE, Garcia-Porrua C, Bentham G, Scott DG. Geoepidemiology of systemic vasculitis: comparison of the incidence in two regions of Europe. Ann Rheum Dis 2001;60:170-2. DOI PubMed PMC

19. Pearce FA, Lanyon PC, Watts RA, Grainge MJ, Abhishek A, Hubbard RB. Novel insights into the aetiology of granulomatosis with polyangiitis-a case-control study using the Clinical Practice Research Datalink. Rheumatology (Oxford) 2018;57:1002-10. DOI PubMed PMC

20. Gómez-Puerta JA, Gedmintas L, Costenbader KH. The association between silica exposure and development of ANCA-associated vasculitis: systematic review and meta-analysis. Autoimmun Rev 2013;12:1129-35. DOI PubMed PMC

21. Lane SE, Watts RA, Bentham G, Innes NJ, Scott DG. Are environmental factors important in primary systemic vasculitis? Arthritis Rheum 2003;48:814-23. DOI PubMed

22. Stamp LK, Chapman PT, Francis J, et al. Association between environmental exposures and granulomatosis with polyangiitis in Canterbury, New Zealand. Arthritis Res Ther 2015;17:333. DOI PubMed PMC

23. Brinkmann V, Reichard U, Goosmann C, et al. Neutrophil extracellular traps kill bacteria. Science 2004;303:1532-5. DOI PubMed

24. Sangaletti S, Tripodo C, Chiodoni C, et al. Neutrophil extracellular traps mediate transfer of cytoplasmic neutrophil antigens to myeloid dendritic cells toward ANCA induction and associated autoimmunity. Blood 2012;120:3007-18. DOI PubMed

25. Hakkim A, Fürnrohr BG, Amann K, et al. Impairment of neutrophil extracellular trap degradation is associated with lupus nephritis. Proc Natl Acad Sci U S A 2010;107:9813-8. DOI PubMed PMC

26. Nakazawa D, Shida H, Tomaru U, et al. Enhanced formation and disordered regulation of NETs in myeloperoxidase-ANCA-associated microscopic polyangiitis. J Am Soc Nephrol 2014;25:990-7. DOI PubMed PMC

27. Hiwa R, Ohmura K, Arase N, et al. Myeloperoxidase/HLA Class II complexes recognized by autoantibodies in microscopic polyangiitis. Arthritis Rheumatol 2017;69:2069-80. DOI PubMed

28. Leacy E, Brady G, Little MA. Pathogenesis of ANCA-associated vasculitis: an emerging role for immunometabolism. Rheumatology (Oxford) 2020;59:iii33-41. DOI PubMed

29. Kronbichler A, Lee KH, Denicolò S, et al. Immunopathogenesis of ANCA-associated vasculitis. Int J Mol Sci 2020;21:7319. DOI PubMed PMC

30. Xiao H, Schreiber A, Heeringa P, Falk RJ, Jennette JC. Alternative complement pathway in the pathogenesis of disease mediated by anti-neutrophil cytoplasmic autoantibodies. Am J Pathol 2007;170:52-64. DOI PubMed PMC

31. Schreiber A, Xiao H, Jennette JC, Schneider W, Luft FC, Kettritz R. C5a receptor mediates neutrophil activation and ANCA-induced glomerulonephritis. J Am Soc Nephrol 2009;20:289-98. DOI PubMed PMC

32. Nakazawa D, Shida H, Kusunoki Y, et al. The responses of macrophages in interaction with neutrophils that undergo NETosis. $J$ Autoimmun 2016;67:19-28. DOI PubMed

33. Chen M, Kallenberg CG. ANCA-associated vasculitides--advances in pathogenesis and treatment. Nat Rev Rheumatol 2010;6:653-64. DOI PubMed

34. Stegeman C, Tervaert J, de Jong P. Trimethoprim-sulfamethoxazole (co-trimoxazole) for the prevention of relapses of Wegener's granulomatosis. Am J Ophthalmol 1996;122:606. DOI PubMed

35. Polzer K, Karonitsch T, Neumann T, et al. Eotaxin-3 is involved in Churg-Strauss syndrome--a serum marker closely correlating with disease activity. Rheumatology (Oxford) 2008;47:804-8. DOI PubMed

36. Csernok E, Hellmich B. Usefulness of vasculitis biomarkers in the era of the personalized medicine. Autoimmun Rev 2020;19:102514. DOI PubMed

37. Brogan P, Eleftheriou D. Vasculitis update: pathogenesis and biomarkers. Pediatr Nephrol 2018;33:187-98. DOI PubMed PMC

38. Roth AJ, Ooi JD, Hess JJ, et al. Epitope specificity determines pathogenicity and detectability in ANCA-associated vasculitis. $J$ Clin Invest 2013;123:1773-83. DOI PubMed PMC

39. Lally L, Spiera RF. Biomarkers in ANCA-associated vasculitis. Curr Rheumatol Rep 2013;15:363. DOI PubMed

40. Morris AD, Rowbottom AW, Martin FL, Woywodt A, Dhaygude AP. Biomarkers in ANCA-associated vasculitis: potential pitfalls and future prospects. Kidney360 2021;2:586-97. DOI

41. Domingues VM, Machado B, Santos J. ANCA-positive vasculitis: clinical implications of ANCA types and titers. Rev Assoc Med Bras (1992) 2016;62:434-40. DOI PubMed

42. Suwanchote S, Rachayon M, Rodsaward P, et al. Anti-neutrophil cytoplasmic antibodies and their clinical significance. Clin Rheumatol 2018;37:875-84. DOI PubMed

43. FijoŁek J, Wiatr E. Antineutrophil cytoplasmic antibodies (ANCA) - their role in pathogenesis, diagnosis, and treatment monitoring of ANCA-associated vasculitis. Cent Eur J Immunol 2020;45:218-27. DOI PubMed PMC 
44. Gou SJ, Xu PC, Chen M, Zhao MH. Epitope analysis of anti-myeloperoxidase antibodies in patients with ANCA-associated vasculitis. PLoS One 2013;8:e60530. DOI PubMed PMC

45. Renn JH, Yang NP, Chueh CM, Lin CY, Lan TH, Chou P. Bone mass in schizophrenia and normal populations across different decades of life. BMC Musculoskelet Disord 2009;10:1. DOI PubMed PMC

46. Fussner LA, Hummel AM, Schroeder DR, et al; Rituximab in ANCA-Associated Vasculitis-Immune Tolerance Network Research Group. Factors determining the clinical utility of serial measurements of antineutrophil cytoplasmic antibodies targeting proteinase 3 . Arthritis Rheumatol 2016;68:1700-10. DOI PubMed PMC

47. Schönermarck U, Lamprecht P, Csernok E, Gross WL. Prevalence and spectrum of rheumatic diseases associated with proteinase 3antineutrophil cytoplasmic antibodies (ANCA) and myeloperoxidase-ANCA. Rheumatology (Oxford) 2001;40:178-84. DOI PubMed

48. Mahr A, Katsahian S, Varet H, et al; French Vasculitis Study Group (FVSG) and the European Vasculitis Society (EUVAS). Revisiting the classification of clinical phenotypes of anti-neutrophil cytoplasmic antibody-associated vasculitis: a cluster analysis. Ann Rheum Dis 2013;72:1003-10. DOI PubMed

49. Lionaki S, Blyth ER, Hogan SL, et al. Classification of antineutrophil cytoplasmic autoantibody vasculitides: the role of antineutrophil cytoplasmic autoantibody specificity for myeloperoxidase or proteinase 3 in disease recognition and prognosis. Arthritis Rheum 2012;64:3452-62. DOI PubMed PMC

50. Pepper RJ, Draibe JB, Caplin B, et al; RAVE-Immune Tolerance Network Research Group. Association of serum calprotectin (S100A8/A9) level with disease relapse in proteinase 3-antineutrophil cytoplasmic antibody-associated vasculitis. Arthritis Rheumatol 2017;69:185-93. DOI PubMed PMC

51. Kessenbrock K, Krumbholz M, Schönermarck U, et al. Netting neutrophils in autoimmune small-vessel vasculitis. Nat Med 2009;15:623-5. DOI PubMed PMC

52. Manojlovic M, Juto A, Jonasdottir A, et al. Microparticles expressing myeloperoxidase as potential biomarkers in anti-neutrophil cytoplasmic antibody (ANCA)-associated vasculitides (AAV). J Mol Med (Berl) 2020;98:1279-86. DOI PubMed PMC

53. Lange C, Csernok E, Moosig F, Holle JU. Immune stimulatory effects of neutrophil extracellular traps in granulomatosis with polyangiitis. Clin Exp Rheumatol 2017;35 Suppl 103:33-9. PubMed

54. Barnado A, Crofford LJ, Oates JC. At the bedside: neutrophil extracellular traps (NETs) as targets for biomarkers and therapies in autoimmune diseases. J Leukoc Biol 2016;99:265-78. DOI PubMed PMC

55. Lieberthal JG, Cuthbertson D, Carette S, et al; Vasculitis Clinical Research Consortium. urinary biomarkers in relapsing antineutrophil cytoplasmic antibody-associated vasculitis. J Rheumatol 2013;40:674-83. DOI PubMed PMC

56. Tam FW, Sanders JS, George A, et al. Urinary monocyte chemoattractant protein-1 (MCP-1) is a marker of active renal vasculitis. Nephrol Dial Transplant 2004;19:2761-8. DOI PubMed

57. Ohlsson S, Bakoush O, Tencer J, Torffvit O, Segelmark M. Monocyte chemoattractant protein 1 is a prognostic marker in ANCAassociated small vessel vasculitis. Mediators Inflamm 2009;2009:584916. DOI PubMed PMC

58. O'Reilly VP, Wong L, Kennedy C, et al. Urinary soluble CD163 in active renal vasculitis. J Am Soc Nephrol 2016;27:2906-16. DOI PubMed PMC

59. Nagai M, Hirayama K, Ebihara I, Higuchi T, Shimohata H, Kobayashi M. Serum levels of the soluble haemoglobin scavenger receptor CD163 in MPO-ANCA-associated renal vasculitis. Scand J Rheumatol 2016;45:397-403. DOI PubMed

60. Monach PA, Warner RL, Tomasson G, et al. Serum proteins reflecting inflammation, injury and repair as biomarkers of disease activity in ANCA-associated vasculitis. Ann Rheum Dis 2013;72:1342-50. DOI PubMed PMC

61. Dallos T, Heiland GR, Strehl J, et al. CCL17/thymus and activation-related chemokine in Churg-Strauss syndrome. Arthritis Rheum 2010;62:3496-503. DOI PubMed

62. Vaglio A, Strehl JD, Manger B, et al. IgG4 immune response in Churg-Strauss syndrome. Ann Rheum Dis 2012;71:390-3. DOI PubMed

63. Pepper RJ, Hamour S, Chavele KM, et al. Leukocyte and serum S100A8/S100A9 expression reflects disease activity in ANCAassociated vasculitis and glomerulonephritis. Kidney Int 2013;83:1150-8. DOI PubMed PMC

64. Szczeklik W, Sanak M, Mastalerz L, et al. 12-hydroxy-eicosatetraenoic acid (12-HETE): a biomarker of Churg-Strauss syndrome. Clin Exp Allergy 2012;42:513-22. DOI PubMed

65. Henes FO, Chen Y, Bley TA, et al. Correlation of serum level of high mobility group box 1 with the burden of granulomatous inflammation in granulomatosis with polyangiitis (Wegener's). Ann Rheum Dis 2011;70:1926-9. DOI PubMed

66. Brogan PA, Dillon MJ. Endothelial microparticles and the diagnosis of the vasculitides. Intern Med 2004;43:1115-9. DOI PubMed

67. Clarke LA, Hong Y, Eleftheriou D, et al. Endothelial injury and repair in systemic vasculitis of the young. Arthritis Rheum 2010;62:1770-80. DOI PubMed

68. Erdbruegger U, Grossheim M, Hertel B, et al. Diagnostic role of endothelial microparticles in vasculitis. Rheumatology (Oxford) 2008;47:1820-5. DOI PubMed

69. Eleftheriou D, Hong Y, Klein NJ, Brogan PA. Thromboembolic disease in systemic vasculitis is associated with enhanced microparticle-mediated thrombin generation. J Thromb Haemost 2011;9:1864-7. DOI PubMed

70. Eleftheriou D, Ganesan V, Hong Y, Klein NJ, Brogan PA. Endothelial injury in childhood stroke with cerebral arteriopathy: a crosssectional study. Neurology 2012;79:2089-96. DOI PubMed PMC

71. Woywodt A, Streiber F, de Groot K, Regelsberger H, Haller H, Haubitz M. Circulating endothelial cells as markers for ANCAassociated small-vessel vasculitis. Lancet 2003;361:206-10. DOI PubMed

72. Závada J, Kideryová L, Pytlík R, Hrusková Z, Tesar V. Reduced number of endothelial progenitor cells is predictive of early relapse in anti-neutrophil cytoplasmic antibody-associated vasculitis. Rheumatology (Oxford) 2009;48:1197-201. DOI PubMed 
73. Cantin L, Chartrand-Lefebvre C, Marcotte F, Pressacco J, Ducharme A, Lapierre C. Coronary artery noninvasive imaging in adult Kawasaki disease. Clin Imaging 2009;33:181-7. DOI PubMed

74. van Dam LS, Dirikgil E, Bredewold EW, et al. Proteinase-3-anti-neutrophil cytoplasmic antibodies (PR3-ANCAs) predict relapses in ANCA-associated vasculitis patients after rituximab. Nephrol Dial Transplant 2020:gfaa066. DOI PubMed

75. Smith RM, Jones RB, Guerry MJ, et al. Rituximab for remission maintenance in relapsing antineutrophil cytoplasmic antibodyassociated vasculitis. Arthritis Rheum 2012;64:3760-9. DOI PubMed

76. Bunch DO, McGregor JG, Khandoobhai NB, et al. Decreased $\mathrm{CD}^{+}$B cells in active ANCA vasculitis and relapse after rituximab. Clin J Am Soc Nephrol 2013;8:382-91. DOI PubMed PMC

77. Unizony S, Lim N, Phippard DJ, et al. Peripheral CD5+ B cells in antineutrophil cytoplasmic antibody-associated vasculitis. Arthritis Rheumatol 2015;67:535-44. DOI PubMed PMC

78. Bader L, Koldingsnes W, Nossent J. B-lymphocyte activating factor levels are increased in patients with Wegener's granulomatosis and inversely correlated with ANCA titer. Clin Rheumatol 2010;29:1031-5. DOI PubMed

79. Dolff S, Witzke O, Wilde B. Th17 cells in renal inflammation and autoimmunity. Autoimmun Rev 2019;18:129-36. DOI PubMed

80. von Borstel A, Lintermans LL, Heeringa P, et al. Circulating CD24hiCD38hi regulatory B cells correlate inversely with the ThEM17 cell frequency in granulomatosis with polyangiitis patients. Rheumatology (Oxford) 2019. DOI PubMed

81. Guillevin L, Pagnoux C, Karras A, et al. Rituximab versus azathioprine for maintenance in ANCA-associated vasculitis. A prospective study in 117 patients. La Presse Médicale 2013;42:679. DOI

82. Li K, Zhang Y, Zhang Y, et al. Tyrosine kinase Fyn promotes osteoarthritis by activating the $\beta$-catenin pathway. Ann Rheum Dis 2018;77:935-43. DOI PubMed

83. Wang Y, Zhang S, Zhang N, et al. Reduced activated regulatory T cells and imbalance of Th17/activated Treg cells marks renal involvement in ANCA-associated vasculitis. Mol Immunol 2020;118:19-29. DOI PubMed

84. Deng J, Wei Y, Fonseca VR, Graca L, Yu D. T follicular helper cells and T follicular regulatory cells in rheumatic diseases. Nat Rev Rheumatol 2019;15:475-90. DOI PubMed

85. Gou SJ, Yuan J, Wang C, Zhao MH, Chen M. Alternative complement pathway activation products in urine and kidneys of patients with ANCA-associated GN. Clin J Am Soc Nephrol 2013;8:1884-91. DOI PubMed PMC

86. Tesar V, Hruskova Z. Avacopan in the treatment of ANCA-associated vasculitis. Expert Opin Investig Drugs 2018;27:491-6. DOI PubMed

87. Yuan J, Gou SJ, Huang J, Hao J, Chen M, Zhao MH. C5a and its receptors in human anti-neutrophil cytoplasmic antibody (ANCA)associated vasculitis. Arthritis Res Ther 2012;14:R140. DOI PubMed PMC

88. Gou SJ, Yuan J, Chen M, Yu F, Zhao MH. Circulating complement activation in patients with anti-neutrophil cytoplasmic antibodyassociated vasculitis. Kidney Int 2013;83:129-37. DOI PubMed

89. Jayne DRW, Merkel PA, Schall TJ, Bekker P; ADVOCATE Study Group. Avacopan for the Treatment of ANCA-Associated Vasculitis. N Engl J Med 2021;384:599-609. DOI PubMed

90. Manenti L, Vaglio A, Gnappi E, et al. Association of serum C3 concentration and histologic signs of thrombotic microangiopathy with outcomes among patients with ANCA-associated renal vasculitis. Clin J Am Soc Nephrol 2015;10:2143-51. DOI PubMed PMC 